\title{
Hepatitis B screening prior to chemotherapy in the Middle East: A retrospective cohort study
}

\section{Abstract}

Background: Hepatitis B virus (HBV) reactivation can be asymptomatic or manifest as fatal fulminant hepatitis. Most international guidelines recommend screening patients prior to immunosuppressive therapy.

Aims: To determine HBV screening rates and modalities in patients receiving chemotherapy at the American University of Beirut Medical Center.

Methods: A retrospective cohort review of electronic health records of adult patients who received chemotherapeutic agents, between June 2015 and June 2016. Patients clinical characteristics were documented. Adequate screening was defined as performing all: HBsAg, HBs Abs, and anti $\mathrm{HBC}$ Abs (total).

Results: A total of 1547 patients were initially assessed. $45.6 \%$ were males with a mean age of $56.382(30 \%)$ had hematologic malignancies, of whom 111 underwent HSCT. Of those included, 303 (24\%) patients were screened by at least one test for HBV and 42 (3.3\%) for HBsAg, anti HBc Abs and HBs Abs.

Patients who were appropriately screened were significantly younger $(p=0.008)$ and more likely to have hematologic malignancies $(n=35$, $83.3 \%, p<0.0001)$. Among patients with hematologic malignancies, appropriately screened patients $(n=35)$ were younger $(p=0.042)$ and had a history of HSCT $(n=19,54.3 \%, p=0.001)$.

Conclusion: Rates of screening for HBV prior to chemotherapy at our medical center are low, and not always complete or adequate. There is an urgent need to implement a better screening policy.

Keywords

Hepatitis B Virus; Antineoplastic Agents; Screening Tests.
Nathalie Ziade ${ }^{1}$, Mohammad Hosni ${ }^{1}$, Kassem Barada ${ }^{1}$, Abdul Rahman Bizri²

1 Division of Gastroenterology, Department of Internal Medicine, American University of Beirut Medical Center, Beirut, Lebanon.

2 Division of Infectious Diseases, Department of Internal Medicine, American University of Beirut Medical Center, Beirut, Lebanon.

\section{Contact information:}

Abdul Rahman Bizri, MD.

Address: Professor of Medicine, Division of Infectious Diseases, Department of Internal Medicine, American University of Beirut Medical Center, Beirut, Lebanon.

झab00@aub.edu.lb 


\section{Introduction}

The global burden of hepatitis B virus (HBV) infection has been increasingly recognized. Viral hepatitis $B$ and $C$ are associated with significant morbidity and mortality [1]. Chronic HBV infection affects $6 \%$ of the world's population [2]. It caused 686000 deaths in 2013, placing it among the 20 most common causes of mortality worldwide [3]. Endemicity varies worldwide between $<2 \%$ and $>8 \%$ (low and high, respectively [4]. In the Middle East, Lebanon is considered to be of moderate endemicity along with Turkey and Pakistan, while Saudi Arabia and Jordan are highly endemic for HBV infection $[5,6]$.

The pool of immunocompromised patients is ever increasing and it encompasses patients receiving chemotherapy and anti-CD20 monoclonal antibodies for neoplastic disorders, organ and bone marrow transplantation, those on chronic steroid therapy, and those on biological agents such as anti-tumor necrosis factor (anti-TNF).

In immunocompetent hosts, HBV infection usually causes acute hepatitis that resolves spontaneously in most patients. This results in HBsAg seronegativity with persistently detectable antibodies against hepatitis B core antigen (anti-HBc) and/or against Hepatitis B surface antigen (anti-HBs). Despite that, HBV DNA can persist for years in hepatocytes, allowing the virus to replicate in certain immunosuppressive conditions [7]. The risk of reactivation depends greatly on the type of immunosuppressive agent used. Clinically, reactivation can be asymptomatic or may cause fatal fulminant hepatitis. It typically occurs in patients with detectable HBsAg, and less frequently in those with resolved infection (negative $\mathrm{HBsAg}$ with positive anti-HBC and/or antiHBs) [8].

The incidence of reactivation in patients seropositive for $\mathrm{HBs} A g$ receiving rituximab can be as high as $59-80 \%$ [9]. Meanwhile, liver failure rates in patients with positive $\mathrm{HBsAg}$ and anti-HBc, who received chemotherapy, can reach $13.9 \%$ [10].
The US Food and Drug Administration (FDA) included HBV reactivation in the boxed warning of anti-CD20 monoclonal antibodies in 2013, and recommends screening for HBV before administration of the drug [11]. HBV reactivation is diagnosed when reverse seroconversion from a negative to a positive $\mathrm{HBsAg}$ (in patients with positive anti-HBC) or when HBV DNA increases from the baseline. A rise in serum aminotransferases usually follows, indicating a hepatitis flare [12].

One study performed in Egypt screened children receiving chemotherapy for hematological malignancies, and concluded that $79 \%$ of them had detectable HBsAg and/or HBV DNA levels, of whom $70 \%$ developed viral reactivation [13].

HBV screening was shown to be cost-effective in cancer patients prior to rituximab (an anti-CD20) and chemotherapy, specifically in the case of hematopoietic stem cell transplantation [14]. Therefore, all patients who are anticipated to receive immunosuppressive therapy should be screened to assess their risk of reactivation. Screening should include checking for serum HBV markers (HBsAg, anti-HBC, and possibly anti-HBs). Individuals with positive serology need to have their HBV DNA levels determined and antiviral prophylaxis initiated to minimize risk of reactivation. [15].

Despite the increasing rate of HBV screening prior to immunosuppression, it remains suboptimal reaching $28 \%$ even in patients at risk for acquiring HBV [16], and $70 \%$ in patients with non-Hodgkin lymphoma who are planned to receive anti-CD20 [17].

\section{Screening recommendations}

Various scientific bodies strongly recommend screening for hepatitis B for all cancer patients before chemotherapy and prophylactic interventions. The American Association for the Study of Liver Diseases (AASLD) and the Asian Pacific Association for the Study of the Liver (APASL) recommend testing for HBsAg and anti-HBC (IgG or total antibodies). AntiHBs antibodies can also be helpful but their role is 
not well established $[12,18]$. Screening should include all three serologic tests (HBsAg, anti-HBc and anti-HBs) according to the recent European Association for the Study of the Liver (EASL) guidelines [19] and the Center for Disease Control (CDC) [20]. The American Gastroenterological Association (AGA) recommends testing for $\mathrm{HBsAg}$ and anti-HBC and HBV DNA quantitation if any of the serologic tests was positive in moderate and high risk patients (14). The American Society of Clinical Oncology (ASCO) recommends screening all patients before starting anti-CD20 therapy and before hematopoietic stem cell transplantation (high risk for reactivation), and patients at risk for acquiring HBV infection (being born in a country where the prevalence of $\mathrm{HBV}$ is greater than $2 \%$, having sexual contact or living with a person who is HBV infected, IV drug users, those with HIV infection, and patients with high risk behaviors) prior to chemotherapy. Testing should include HBsAg and anti-HBc IgG antibodies [21].

Whenever HBsAg is positive, antiviral therapy is indicated before but without delaying cancer therapy. In case of HBsAg negativity and anti-HBc positivity, clinicians can initiate antiviral prophylaxis in patients at high risk for reactivation, or can monitor for reactivation by checking HBV DNA and ALT every 3 months while on chemotherapy, then starting antiviral therapy at the first sign of reactivation [21]. Despite all the available recommendations, screening for HBV before initiating chemotherapy and immunosuppressant remains suboptimal.

This study aims to evaluate the screening rates for HBV in a leading tertiary care university medical center in the Middle East, in patients receiving chemotherapy.

\section{Materials and methods}

\section{Study design}

The study is a retrospective cohort review of the electronic health records (EHR) of patients who re- ceived cancer chemotherapy or hematopoietic stem cell transplantation between June 2015 and June 2016. Data was collected electronically, and was saved in a confidential file that only the PI and the Co-investigator have access to. The information retrieved included patients demographics, underlying medical conditions, indication for chemotherapy, and date of treatment initiation. Data about HBV screening, if done, was recorded after searching all the patients laboratory tests performed (since the date of their first encounter until the year 2017), and the type of serological tests done for screening. The Institutional Review Board (protocol number IM.ARB.13) approved the study protocol beforehand.

\section{Patient population}

The inclusion and exclusion criteria are iterated herein:

Inclusion Criteria:

- Patients older than 18 years

- Patients who received chemotherapy

- Hematopoietic stem cell transplant recipients

Exclusion Criteria:

- Patients with known Hepatitis B infection

\section{Study endpoints}

Primary endpoint: the percentage of patients who were screened

Secondary endpoint: the adequacy of screening

\section{Statistical analysis}

Descriptive analysis was performed. Percentages (\%) were used for qualitative valuables and measures of central tendency (mean) were used for quantitative variables. Comparisons were made and variables associated with appropriate hepatitis B screening were assessed using chi-square test for categorical variables and t-test for continuous variables. Multivariate logistic regression analysis was used to adjust for potentially confounding variables. The data was analyzed using statistical software SPSS. 


\section{Results}

A total of 1547 patients were initially assessed, 277 were excluded from the study (221 were younger than 18, and 56 did not receive chemotherapy). The mean age was 56 (range 18 to 96 ) and $45.6 \%$ were males.888 out of 1270 (70\%) patients had solid organ malignancies, and the rest (382 or 30\%) had hematologic malignancies, of whom 111 underwent hematopoietic stem cell transplantation (HSCT) (Table 1). The majority were not screened

Table 1. General characteristics of the studied population.

\begin{tabular}{|c|c|c|c|}
\hline \multicolumn{2}{|c|}{ Descriptive statistics } & No. & $\%$ \\
\hline \multicolumn{2}{|c|}{ Age (mean, SD) } & 56.2 & 16.6 \\
\hline \multicolumn{2}{|c|}{ Gender (Female) } & 691 & 54.4 \\
\hline \multicolumn{4}{|c|}{ Type of Tumor } \\
\hline \multirow{3}{*}{$\begin{array}{l}\text { A. } \\
\text { Hematologic } \\
\text { malignancy }\end{array}$} & $\begin{array}{l}\text { Leukemia, n (\% among } \\
\text { hematologic malignancies) }\end{array}$ & 124 & 32.5 \\
\hline & $\begin{array}{l}\text { Lymphoma, } \mathrm{n} \text { ( } \% \text { among } \\
\text { hematologic malignancies) }\end{array}$ & 182 & 47.7 \\
\hline & $\begin{array}{l}\text { Other1, } \mathrm{n} \text { (\% among } \\
\text { hematologic malignancies) }\end{array}$ & 76 & 19.8 \\
\hline \multirow{5}{*}{$\begin{array}{l}\text { B. } \\
\text { Solid organ } \\
\text { malignancy }\end{array}$} & $\begin{array}{l}\text { Breast, } \mathrm{n} \text { (\% among solid } \\
\text { malignancies) }\end{array}$ & 304 & 34.2 \\
\hline & $\begin{array}{l}\text { Genitourinary, } \mathrm{n}(\% \text { among } \\
\text { solid malignancies) }\end{array}$ & 157 & 17.7 \\
\hline & $\begin{array}{l}\text { Gastrointestinal tract, } \mathrm{n}(\% \\
\text { among solid malignancies) }\end{array}$ & 148 & 16.7 \\
\hline & $\begin{array}{l}\text { Lung, n (\% among solid } \\
\text { malignancies) }\end{array}$ & 119 & 13.4 \\
\hline & $\begin{array}{l}\text { Other }{ }^{2}, \mathrm{n} \text { (\% among solid } \\
\text { malignancies) }\end{array}$ & 160 & 18.0 \\
\hline \multicolumn{2}{|c|}{$\begin{array}{l}\text { History of HSCT (among hematologic } \\
\text { malignancies) }\end{array}$} & 111 & 29.3 \\
\hline \multicolumn{4}{|c|}{ HBV tests performed } \\
\hline \multicolumn{2}{|l|}{ None } & 967 & 76.1 \\
\hline \multicolumn{2}{|c|}{ Any test performed } & 303 & 23.9 \\
\hline \multicolumn{2}{|c|}{$\mathrm{HBsAg}, \mathrm{HBs}$ Abs, and anti HBc total Abs } & 42 & 3.3 \\
\hline \multicolumn{4}{|c|}{$\begin{array}{r}\text { SD: Standard deviation; HBV: Hepatitis B virus; HSCT: } \\
\text { Hematopoietic stem cell transplant; 1: A plastic anemia, } \\
\text { multiple myeloma, myelodysplastic syndromes; } \\
\text { 2: Adrenal carcinoma, central nervous system tumors, } \\
\text { head and neck cancers, hepato-pancreato-biliary } \\
\text { tumors, melanomas, sarcomas, thyroid tumors. }\end{array}$} \\
\hline
\end{tabular}

Table 2. Hepatitis B screening rates according to solid organ and hematologic malignancies.

\begin{tabular}{|c|c|c|c|c|c|c|c|c|}
\hline \multirow{5}{*}{$\begin{array}{c}\text { Test } \\
\text { performed }\end{array}$} & \multirow{2}{*}{\multicolumn{2}{|c|}{$\begin{array}{l}\text { Solid organ } \\
\text { malignancies }\end{array}$}} & \multirow{2}{*}{\multicolumn{4}{|c|}{$\begin{array}{c}\text { Hematologic } \\
\text { malignancies } \\
n=382\end{array}$}} & \multirow{2}{*}{\multicolumn{2}{|c|}{ Total }} \\
\hline & & & & & & & & \\
\hline & \multirow{2}{*}{\multicolumn{2}{|c|}{$n=888$}} & \multirow{2}{*}{\multicolumn{2}{|c|}{$\begin{array}{l}\text { HSCT } \\
n=111\end{array}$}} & \multirow{2}{*}{\multicolumn{2}{|c|}{$\begin{array}{c}\text { No HSCT } \\
n=271\end{array}$}} & \multirow{2}{*}{\multicolumn{2}{|c|}{$n=1270$}} \\
\hline & & & & & & & & \\
\hline & No. & $\%$ & No. & $\%$ & No. & $\%$ & No. & $\%$ \\
\hline None & 826 & 93 & 3 & 2.7 & 138 & 50.9 & 967 & 76.2 \\
\hline $\begin{array}{l}\text { At least } \\
\text { one test }\end{array}$ & 62 & 7 & 108 & 97.3 & 133 & 49.1 & 303 & 23.8 \\
\hline $\begin{array}{l}\text { HBsAg } \\
\text { only }\end{array}$ & 35 & 3.9 & 63 & 57.1 & 60 & 22.1 & 158 & 12.44 \\
\hline $\begin{array}{l}\text { HBs Abs } \\
\text { only }\end{array}$ & 5 & 0.6 & 0 & & 3 & 1.1 & 8 & 0.63 \\
\hline $\begin{array}{l}\text { HBsAg and } \\
\text { Abs }\end{array}$ & 7 & 0.8 & 9 & 8 & 29 & 10.7 & 45 & 3.54 \\
\hline $\begin{array}{l}\text { HBsAg and } \\
\text { anti } \mathrm{HBC} \\
\text { total Abs }\end{array}$ & 8 & 0.9 & 17 & 15.2 & 25 & 9.2 & 50 & 3.93 \\
\hline $\begin{array}{l}\text { HBsAg, } \\
\text { HBs Abs, } \\
\text { and anti } \\
\text { HBc total } \\
\text { Abs }\end{array}$ & 7 & 0.8 & 19 & 17 & 16 & 5.9 & 42 & 3.3 \\
\hline
\end{tabular}

for hepatitis B (967 out of 1270 (76.1\%). Only 3.3\% (42) were screened with all of HBsAg, HBs Abs, and anti $\mathrm{HBC}$ total antibodies (7 in solid organ and 35 in hematologic malignancies). 45 patients (3.5\%) were tested for HBsAg and HBs Abs, and 50 patients (3.9\%) tested for HBsAg and anti HBC total antibodies. A total of 303 patients (62 in solid malignancies, 241 in hematologic malignancies) were screened for any of the HBsAg, HBs Abs, or anti $\mathrm{HBC}$ total antibodies, and 158 (12.4\%) were tested for HBsAg alone (Table 2). Among those who tested positive for any of the previously mentioned tests (in addition to HBeAg or anti HBeAbs) 20 out of 25 were checked for HBV DNA. To further understand the factors associated with physician's decision in performing appropriate HBV screening, we compared those who were appropriately screened to those who were not (Table 3). As shown in Table 3, patients who were appropriately screened 
Vol. 10 No. 1:4 doi: $10.3823 / 842$
Table 3. Comparing patients who were partially or not screened to patients with the appropriate screening for Hepatitis B.

\begin{tabular}{|c|c|c|c|c|}
\hline & $\begin{array}{l}\text { Appropriate } \\
\text { screening }\end{array}$ & $\begin{array}{c}\text { Partial } \\
\text { screening/ } \\
\text { none }\end{array}$ & \multirow[t]{2}{*}{$p$-value } \\
\hline & & $n=42$ & $n=1228$ & \\
\hline \multicolumn{2}{|c|}{ Age (mean, SD) } & $49.5(19.4)$ & $56.4(16.4)$ & 0.008 \\
\hline \multirow{2}{*}{ Male } & $\mathrm{n}$ & 24 & 555 & \multirow{2}{*}{0.126} \\
\hline & $\%$ & 57.1 & 45.2 & \\
\hline \multirow{2}{*}{$\begin{array}{l}\text { Hematologic } \\
\text { malignancy }\end{array}$} & $\mathrm{n}$ & 24 & 555 & \multirow{2}{*}{$<0.0001$} \\
\hline & $\%$ & 57.1 & 45.2 & \\
\hline \multicolumn{5}{|c|}{ Among hematologic malignancies } \\
\hline & & $\begin{array}{l}\text { Appropriate } \\
\text { screening }\end{array}$ & $\begin{array}{c}\text { Partial } \\
\text { screening/ } \\
\text { none }\end{array}$ & \multirow[t]{2}{*}{ p-value } \\
\hline & & $n=35$ & $n=347$ & \\
\hline \multicolumn{2}{|c|}{ Age (mean, SD) } & $46.2(18.9)$ & $53.3(20.3)$ & 0.042 \\
\hline \multirow{2}{*}{ Male } & $n$ & 21 & 221 & \multirow{2}{*}{0.66} \\
\hline & $\%$ & 60 & 63.7 & \\
\hline \multirow{2}{*}{$\begin{array}{l}\text { History of } \\
\text { HSCT }\end{array}$} & $\mathrm{n}$ & 19 & 92 & \multirow{2}{*}{$<0.0001$} \\
\hline & $\%$ & 54.3 & 26.5 & \\
\hline
\end{tabular}

(42 patietns) were significantly younger $(p=0.008)$ and were more likely to have hematologic malignancy $(n=35,83.3 \%, p<0.0001)$ On multivariate analysis, having hematologic malignancy compared to solid malignancy was an independent predictor of performing appropriate screening ( $O R=11.87$, $95 \% \mathrm{Cl}$ [5.19-27.17], $\mathrm{p}<0.0001)$. Among patients who had hematologic malignancies, those who were appropriately screened $(n=35)$ were younger in age $(p=0.042)$ and had a history of HSCT $(n=19$, $54.3 \%, p=0.001$ ). on multivariate analysis, having a history of HSCT was an independent predictor of performing appropriate screening ( $\mathrm{OR}=3.02,95 \%$ Cl [1.48-6.15], $p=0.002$ ).

\section{Discussion}

Although HBV screening rates have increased over time, as shown between 2002 and 2010 [22], a recent study performed in the United States has shown that screening before chemotherapy (with HBsAg and anti HBc Abs) was performed in only $17 \%$ of cancer patients (excluding patients undergoing HSCT) [23]. Transplant specialists screened their patients most frequently (85\%) compared to gastroenterologists who screened the least (34\%) [24].

In the Middle East, very few studies assess HBV screening in adults prior to chemotherapy. And data on the rate or adequacy of screening remain scarce. National HBV screening programs that include patients who are planned for chemotherapy, or as part of the pre-transplant work-up, are being applied in Saudi Arabia and Jordan, but are not implemented in Egypt, Pakistan, Qatar, Syria, Turkey or UAE $[6,25]$.

In fact, the Saudi Association for the Study of Liver diseases and Transplantation (SASLT) released practice guidelines in 2014 stating that HBV screening is indicated for all patients receiving immunosuppressive or chemotherapy (by testing for HBsAg, anti-HBs and anti-HBc antibodies) [26].

Our medical institution receives many high risk immunocompromised patients for further management of their health conditions. The ever increasing pool of bone marrow transplant patients and hematologic malignancies, as well as the growing number of patients receiving immunosuppressive medications, makes a strong case for HBV screening and evaluation of patients before starting them on long term immunosuppression.

Our study demonstrated that the rate of adequate screening is very low at our institution despite the initiatives and efforts to screen at risk individuals, manifested by testing for any of the serologic markers. Most of the patients who were screened were those who underwent HSCT considered to be at high risk of HBV reactivation compared to other patients [27]. Younger patients were also screened more frequently, despite the fact the prevalence of HBV has been shown to increase with age [28], and 
that viral reactivation could have more deleterious effects in older patients with potentially more comorbidities than younger adults.

The type of chemotherapy administered could not be assessed because of the small number of patients included. This could represent a limitation, along with the retrospective nature of the study.

Despite all available recommendations, HBV screening remains suboptimal, and this places patients at risk of reactivation. Possible explanations include lack of established local guidelines and decreased awareness among physicians concerning the risk of HBV reactivation and its potential deleterious effects. Although some services such as The Bone Marrow Transplant Center at our center have HBV screening integrated into their pre-transplant protocol, many other services acknowledge the need for screening, yet they do not have an established policy for mandatory screening. This needs to be addressed and improved.

Given the variability of recommendations and changing epidemiology and prevalence among various groups, this is the first study in Lebanon and the Middle East to assess the screening rates of HBV prior to chemotherapy and immunosuppressant administration. This may help practicing physicians from different specialties to standardize their practice, and protect their patients. The recent implementation of the EPIC system at our institution can have a major impact on the quality of care of our patients by setting automatic reminders to physicians in order to screen

patients prior to chemotherapy or other immunosuppressive medication, with the adequate recommended serologic tests in a timely manner.

\section{Conclusion}

Screening population at risk for HBV reactivation is still underperformed and not adequately done worldwide and in a leading tertiary care center in the Middle East. Improving awareness among phy- sicians and patients, and implementing a protocoled approach can improve screening rates and therefore decrease the risk of viral reactivation in a vulnerable population, specifically with the increasing use of chemotherapy and immunosuppression.

\section{Declaration of interest}

Nothing to declare (all authors).

This research did not receive any specific grant from funding agencies in the public, commercial, or not-for-profit sectors.

\section{References}

1. Stanaway DJ, Flaxman DA, Naghavi M, Fitzmaurice C, Vos T, Abubakar I et al. The global burden of viral hepatitis from 1990 to 2013: findings from the Global Burden of Disease Study 2013. The Lancet. 2016; 388(10049): 1081-1088.

2. Ott J, Stevens G, Groeger J, Wiersma S, Global epidemiology of hepatitis B virus infection: new estimates of age-specific HBsAg seroprevalence and endemicity. Vaccine 2012; 30:2212-2219.

3. Global, regional, and national age-sex specific all-cause and cause-specific mortality for 240 causes of death, 1990-2013: a systematic analysis for the Global Burden of Disease Study 2013. Crossref DOI link: https://doi.org/10.1016/S01406736(14)61682-2

4. Schweitzer A, Horn J, Mikolajczyk TR, Krause G, Ott JJ. Estimations of worldwide prevalence of chronic hepatitis $B$ virus infection: a systematic review of data published between 1965 and 2013. The Lancet 2015; 386:1546-1555.

5. Nabulsi MM, El Saleeby CM, Araj GF.The current status of hepatitis B in Lebanon. LMJ 2003; 51: 64-70.

6. Specialist Panel on Chronic Hepatitis B in the Middle East. A review of chronic hepatitis $B$ epidemiology and management issues in selected countries in the Middle East. J Viral Hepat 2012; 19: 9-22.

7. Kusumoto $S$, Tobinai $K$. Screening for and management of hepatitis B virus reactivation in patients treated with anti-B-cell therapy. ASH Education Program Book 2014; 576-583.

8. Lok AS, Liang RH, Chiu EK, Wong KL, Chan TK, Todd D. Reactivation of hepatitis $B$ virus replication in patients receiving cytotoxic therapy: report of a prospective study. Gastroenterology 1991; 100:182-188.

9. Kim SJ,Hsu C, Song YQ, Tay K, Hong XN, Cao J et al. Hepatitis $B$ virus reactivation in $B$-cell lymphoma patients treated with rituximab: analysis from the Asia Lymphoma Study Group. Eur J Cancer Prev 2013; 49:3486-3496. 
10. Loomba R, Rowley A, Wesley R, Liang TJ, Hoofnagle JH, Pucino $F$ et al. Systematic review: the effect of preventive lamivudine on hepatitis $B$ reactivation during chemotherapy. Ann. Intern Med 2008; 148: 519-528.

11. Di Bisceglie AM1, Lok AS, Martin P, Terrault N, Perrillo RP, Hoofnagle $\mathrm{JH}$. Recent US Food and Drug Administration warnings on hepatitis $B$ reactivation with immune- suppressing and anticancer drugs: just the tip of the iceberg? Hepatology 2015; 61(2):703-11

12. Terrault NA, Lok ASF, McMahon BJ, Chang KM, Hwang JP, Jonas $\mathrm{MM}$ et al. Update on prevention, diagnosis, and treatment of chronic hepatitis B: AASLD 2018 hepatitis B guidance. Hepatology 2018; 67:1560-1599.

13. El-Sayed MH, Mohamed MM, Maina AM, Oliveri F, Brunetto MR, Bonino F. Severe liver disease is caused by HBV rather than $\mathrm{HCV}$ in children with hematological malignancies. Hematology J 2003, 4(5):321-327.

14. Reddy RK, Beavers LK, Hammond PS, Lim KL, Falck-Ytter YY. American Gastroenterological Association Institute guideline on the prevention and treatment of hepatitis B virus reactivation during immunosuppressive drug therapy. Gastroenterology 2015; 148:215-219.

15. Abubakar I., Tillmann T., Banerjee A. Global, regional, and national age-sex specific all-cause and cause-specific mortality for 240 causes of death, 1990-2013: a systematic analysis for the Global Burden of Disease Study 2013. The Lancet 2015; 385:117-171 (2015).

16. Hwang JP., Fisch MJ., Lok AS, et al. Trends in hepatitis B virus screening at the onset of chemotherapy in a large US cancer center. BMC cancer 2013; 13: 534

17. Neuss MN, Desch CE, McNiff KK, Eisenberg PD, Gesme DH, Jacobson JO, et al. A process for measuring the quality of cancer care: The Quality Oncology Practice Initiative. J Clin Oncol 2005; 23:6233-6239.

18. Sarin SK, Kumar M, Lau GK, Abbas Z, Chan HL, Chen CJ, et al. Asian-Pacific clinical practice guidelines on the management of hepatitis B: a 2015 update. Hepatol. Int 2016; 10, 1-98.

19. Eupropean for the study of Liver. Clinical Practice Guidelines on the management of hepatitis B virus infection. J Hepatol 2017; 67: 370-398.

20. Weinbaum MC, Mast EE, Ward WJ. Recommendations for identification and public health management of persons with chronic hepatitis B virus infection. J. Hepatol 2009; 49:S35-S44.

21. Hwang PJ, A. S. Artz SA, Somerfield RM. Hepatitis B virus screening for patients with cancer before therapy: American Society of Clinical Oncology provisional clinical opinion update. J Oncol Prac 2015; 11: e487-e489.

22. Vaughn PB, Doherty AG, Gautam S, Moss CA, Cheifetz SA. Screening for tuberculosis and hepatitis $B$ prior to the initiation of anti-tumor necrosis therapy. Inflamm Bowel Dis 2011; 18:1057-1063.
23. Hwang JP, Fisch MJ, Zhang $\mathrm{H}$, et al. Low rates of hepatitis $B$ virus screening at the onset of chemotherapy. J Oncol Pract 2012; 8(4):e32-e39.

24. Paul S, Shuja A, Tam I, Kim EM, Kang S, Kapulsky L, et al.Gastroenterologists have suboptimal hepatitis B virus screening rates in patients receiving immunosuppressive therapy. Dig Dis Sci 2016; 61:2236-2241.

25. Nusair M, Rayyan Y, Hammoudeh W, et al. Hepatitis B care pathway in Jordan: current situation, gaps and recommended actions. J Virus Erad 2020; 6(1):1-6. 26.

26. Abaalkhail $F$, Elsiesy H, AlOmair A, Alghamdi MY, Alalwan A, AlMasri N,et al. SASLT practice guidelines for the management of hepatitis B virus. Saudi J Gastroenterol 2014; 20: 5-25.

27. J. Choi Y, Y.-S. Lim SY. Characteristics, Prevention, and Management of Hepatitis B Virus (HBV) Reactivation in HBVInfected Patients Who Require Immunosuppressive Therapy. Int J InfectDis 2017; 216, S778-S784.

28. Lao TT, Sahota SD,. Law WL, Cheng KY, Leung YT. Age-specific prevalence of hepatitis $B$ virus infection in young pregnant women, Hong Kong Special Administrative Region of China. Bull World Health Organ 2014; B; 92:782-789.

\section{Publish in The International} Arabic Journal of Antimicrobial Agents

The Journal is an open access peer-reviewed journal that publishes scientific papers about all aspects of antimicrobials. The journal will publish original research articles, reviews, brief reports and case reports dealing with basic and clinical antibacterial agents, antiviral, antiprotozoals, antituberculuous, antifungal and antihelminthes agents. All manuscripts must be prepared in English, and are subject to a rigorous and fair peer-review process. Accepted papers will immediately appear online. The journal aims to advance the knowledge, attitude and the research of chemotherapy in the Arabic world in cooperation with international, national scientific and public societies as well as research centers with similar aims and objectives. 